\title{
EXPLAINING EXTREME EVENTS OF 2018 From a Climate Perspective
}
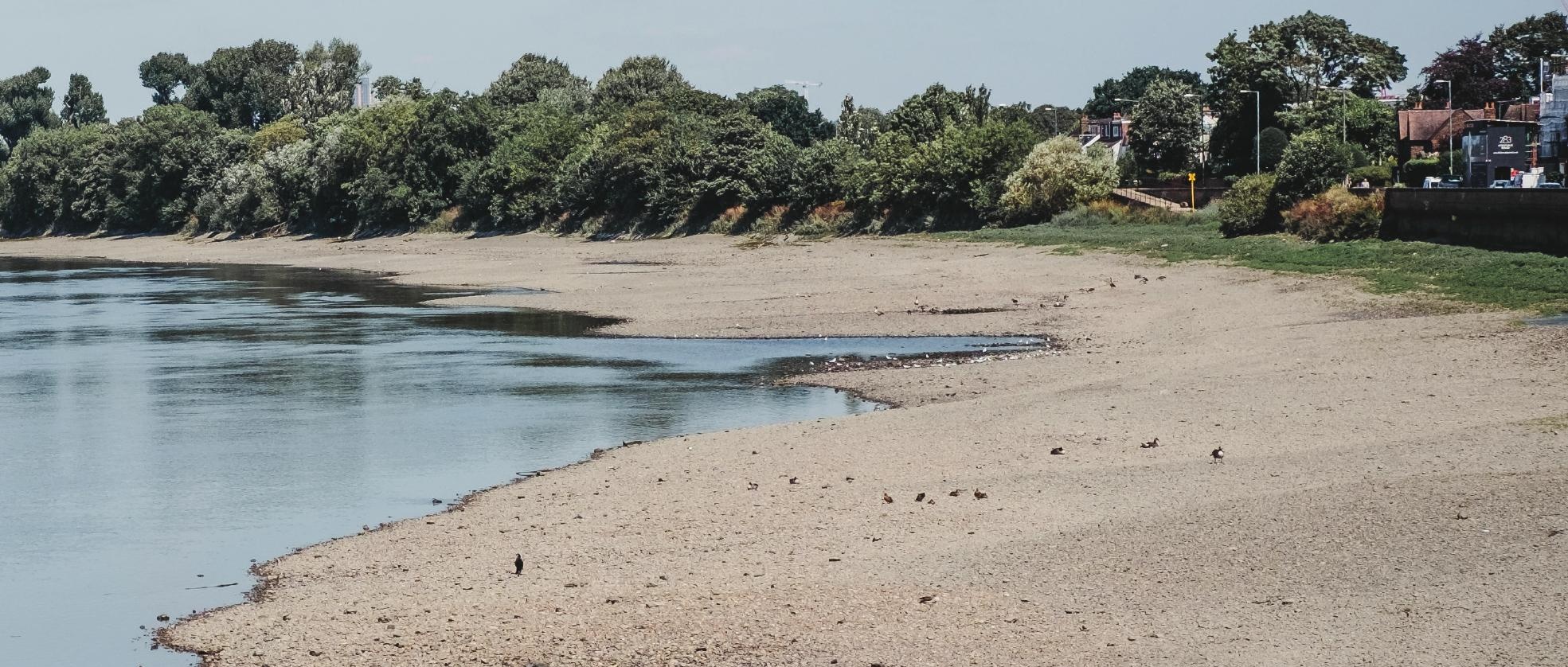

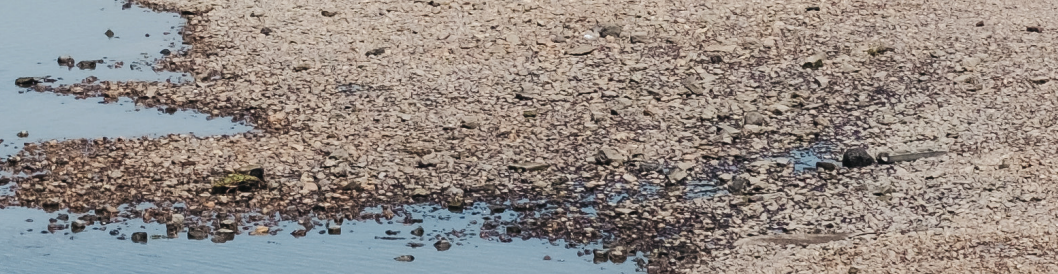

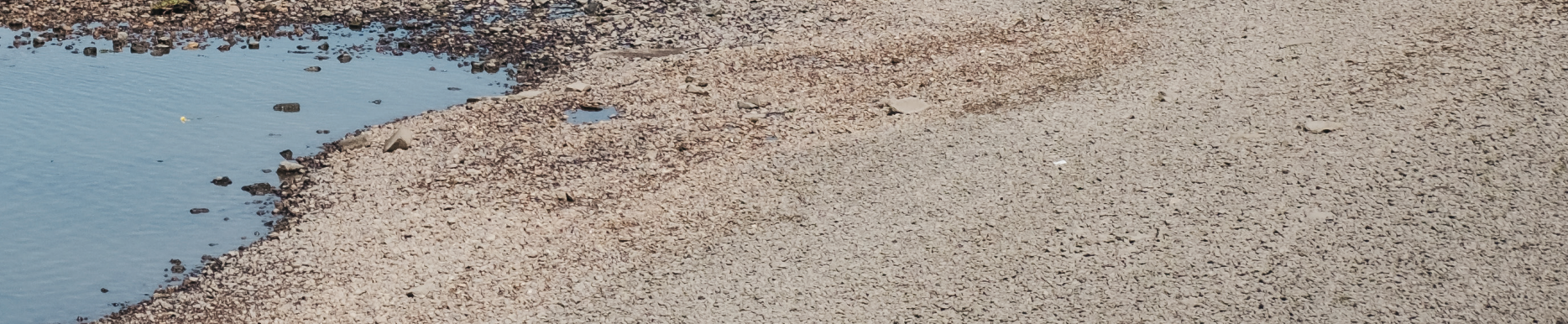

$x^{2}+m^{3}$

1.

Special Supplement to the Bulletin of the American Meteorological Society

7. 01.101 , No. 1 , January 2020 


\title{
EXPLAINING EXTREME EVENTS OF 2018 FROM A CLIMATE PERSPECTIVE
}

\author{
Editors \\ Stephanie C. Herring, Nikolaos Christidis, Andrew Hoell, \\ Martin P. Hoerling, and Peter A. Stott
}

\section{BAMS Special Editors for Climate \\ Andrew King, Thomas Knutson, \\ John Nielsen-Gammon, and Friederike Otto}

Special Supplement to the

Bulletin of the American Meteorological Society

Vol. I OI, No. I, January 2020

American Meteorological Society 
CORRESPONDING EDITOR:

Stephanie C. Herring, PhD

NOAA National Centers for Environmental Information

325 Broadway, E/CC23, Rm IB-I3|

Boulder, CO, 80305-3328

E-mail: stephanie.herring@noaa.gov

Cover CReDit: iStock.com/Alena Kravchenko-River Thames receded during a heatwave in summer 2018 in London, United Kingdom.

\section{HOW TO CITE THIS DOCUMENT}

Citing the complete report:

Herring, S. C., N. Christidis, A. Hoell, M. P. Hoerling, and P. A. Stott, Eds., 2020: Explaining Extreme Events of 2018 from a Climate Perspective. Bull. Amer. Meteor. Soc., I0I (I), SI-SI28, doi:I0.II75/BAMS-ExplainingExtremeEvents20I8.I.

Citing a section (example):

Mahoney, K., 2020: Extreme Hail Storms and Climate Change: Foretelling the Future in Tiny, Turbulent Crystal Balls? [in "Explaining Extremes of 2018 from a Climate Perspective"]. Bull. Amer. Meteor. Soc., I0I (I), SI7-S22, doi:I0.II75/BAMSD-19-0233.I. 


\section{TABLE OF CONTENTS}

I. The Extreme 2018 Northern California Fire Season. . . . . . . . . . . . . . . . . . . I

2. Anthropogenic Impacts on the Exceptional Precipitation of 2018

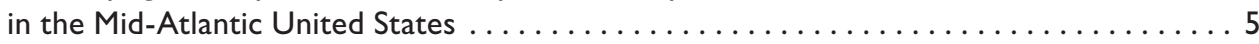

3. Quantifying Human-Induced Temperature Impacts on the 2018 United States Four Corners Hydrologic and Agro-Pastoral Drought . . . . . . . . . . . . . . I

4. Extreme Hail Storms and Climate Change: Foretelling the Future in Tiny, Turbulent Crystal Balls? . . . . . . . . . . . . . . . . . . . . . . . . . . . . . . . . . 17

5. The Extremely Cold Start of the Spring of 2018 in the United Kingdom . . . . . . . . . 23

6. The Exceptional Iberian Heatwave of Summer $2018 \ldots \ldots \ldots \ldots \ldots \ldots . \ldots . \ldots . \ldots 29$

7. Analyses of the Northern European Summer Heatwave of $2018 \ldots \ldots \ldots \ldots \ldots \ldots . \ldots 35$

8. Anthropogenic Influence on the 2018 Summer Warm Spell in Europe:

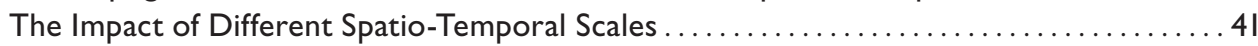

9. On High Precipitation in Mozambique, Zimbabwe and Zambia in February 2018 . . . . . 47

10. The Record Low Bering Sea Ice Extent in 2018: Context, Impacts, and an Assessment of the Role of Anthropogenic Climate Change ............. 53

II. The Late Spring Drought of 2018 in South China...................... 59

12. Anthropogenic Influence on 2018 Summer Persistent Heavy Rainfall

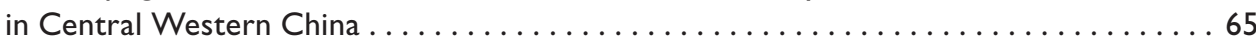

13. Conditional Attribution of the 2018 Summer Extreme Heat over Northeast China: Roles of Urbanization, Global Warming, and Warming-Induced Circulation Changes .... 7 I

14. Effects of Anthropogenic Forcing and Natural Variability on the 2018 Heatwave in Northeast Asia. . . . . . . . . . . . . . . . . . . . 77

15. Anthropogenic Influences on the Persistent Night-Time Heat Wave in Summer 2018 over Northeast China . . . . . . . . . . . . . . . . . . . . . . 83

16. Anthropogenic Contributions to the 2018 Extreme Flooding over the Upper Yellow River Basin in China . . . . . . . . . . . . . . . . . . . . . . . . . . 89

17. Attribution of the Record-Breaking Consecutive Dry Days in Winter 2017/18

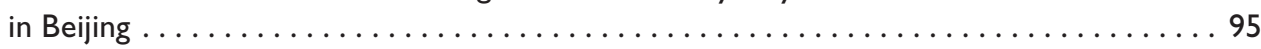

18. Quantifying Human Impact on the 2018 Summer Longest Heat Wave

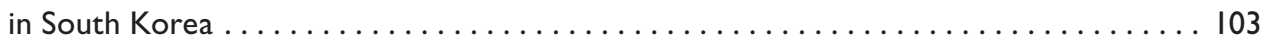

19. The Heavy Rain Event of July 2018 in Japan Enhanced by Historical Warming. . . . . . . 109

20. Deconstructing Factors Contributing to the 2018 Fire Weather in Queensland, Australia ...................................

21. A I-Day Extreme Rainfall Event in Tasmania: Process Evaluation and Long Tail Attribution 


\title{
chapter \\ (1) ANTHROPOGENIC INFLUENCE ON THE 2018 SUMMER WARM SPELL IN EUROPE: THE IMPACT OF DIFFERENT SPATIO-TEMPORAL SCALES
}

\author{
Nicholas J. Leach, Sihan li, Sarah Sparrow, Geert Jan van Oldenborgh, \\ Fraser C. Lott, Antje Weisheimer, and Myles R. Allen
}

We demonstrate that, in attribution studies, events defined over longer time scales generally produce higher probability ratios due to lower interannual variability, reconciling seemingly inconsistent attribution results of Europe's 2018 summer heatwaves in reported studies.

$\mathrm{T}$ he summer of 2018 was extremely warm in parts of Europe, particularly Scandinavia, the Iberian Peninsula, and central Europe, with a range of all-time temperature records set across the continent (Johnston 2018; NESDIS 2018). Impacts were felt across Europe, with wildfires burning in Sweden (Krikken et al. 2019; Watts 2018), heatstroke deaths in Spain (Publico 2018), and widespread drought (Harris 2018). During the summer, the World Weather Attri-

AFFILIATIONS: LEACH-Department of Physics, Atmospheric Oceanic and Planetary Physics, University of Oxford, United Kingdom; LI-Oxford e-Research Centre, Department of Engineering Science, and Environmental Change Institute, School of Geography and the Environment, University of Oxford, United Kingdom; Sparrow-Oxford e-Research Centre, Department of Engineering Science, University of Oxford, United Kingdom; VAN Oldenborgh-Koninklijk Nederlands Meteorologisch Instituut, De Bilt, The Netherlands; LotT-Met Office Hadley Centre, Exeter, United Kingdom; WEISHEIMER-Department of Physics, Atmospheric Oceanic and Planetary Physics, and Department of Physics, National Centre for Atmospheric Science (NCAS), University of Oxford, Oxford, and European Centre for Medium-Range Weather Forecasts (ECMWF), Reading, United Kingdom; AlteN-Department of Physics, Atmospheric Oceanic and Planetary Physics, and Environmental Change Institute, School of Geography and the Environment, University of Oxford, United Kingdom.

CORRESPONDING AUTHOR: Nicholas J. Leach, Nicholas. leach@stx.ox.ac.uk

DOI:I0.1175/BAMS-D-19-0201.I

A supplement to this article is available online (10.II75/BAMS-

D-19-0201.2)

(C) 2020 American Meteorological Society

For information regarding reuse of this content and general copyright information, consult the AMS Copyright Policy. bution (WWA) initiative released an analysis of the heat spell (World Weather Attribution 2018) based on observations/forecasts and models in specific locations (Dublin, Ireland; De Bilt, Netherlands; Copenhagen, Denmark; Oslo, Norway; Linkoping, Sweden; Sodankyla, Finland; Jokionen, Finland), which concluded that the increase in likelihood due to humaninduced climate change was at least 2 to 5 times. In December, the U.K. Met Office (UKMO) stated that they found the 2018 U.K. summer temperatures were made 30 times more likely (Press Office 2018; McCarthy et al. 2019). These two estimates appear to quantitatively disagree; however, we show they can be reconciled by investigating the effects of using different spatial domains and temporal scales in the event definition. We also demonstrate that prescribed SST model simulations can underrepresent the variability of temperature extremes, especially near the coast, with implications for any derived attribution results.

EVENT DEFINITION. We consider various temperature-based event definitions to demonstrate the impact of this choice in attribution assessments, and assess to what extent human influence affected the seasonal and peak magnitudes of the 2018 summer heat event on a range of spatial scales. The statistic we use is the annual maximum of the 1-, 10-, and 90day running mean of daily mean 2 -m temperature (hereafter TM1x, TM10x, and TM90x respectively). We analyze three spatial scales: model grid box, regional, and European. For regional and European event definitions, the spatial mean is calculated before the running mean. Regional extents are taken from Christensen and Christensen (2007), and European extent is the E-OBS (Cornes et al. 2018) domain (land points within $\left.25^{\circ}-71.5^{\circ} \mathrm{N}, 25^{\circ} \mathrm{W}-45^{\circ} \mathrm{E}\right)$. The WWA 
used the annual maxima of 3-day mean daily maximum temperatures at specific grid points for its connection to local health effects (D'Ippoliti et al. 2010), whereas the UKMO used the JJA mean temperature over the entire United Kingdom in order to answer the question of how anthropogenic forcings have affected the likelihood of U.K. summer seasons as warm as 2018. The same justifications can be used here, although we add that different heat event time scales are important to different groups of people, and as such using several temporal definitions may increase interest in heat event attribution studies. However, we recognize that other definitions than those used here may be more relevant to some impacts observed (such as defining the event in the context of the atmospheric flow pattern and drought that accompanied the heat), and other lines of reasoning for selecting one particular event definition exist (Cattiaux and Ribes 2018).

MODEL SIMULATIONS AND VALIDATION. Three sets of simulations from the UKMO Hadley Centre HadGEM3-A global atmospheric model (Christidis et al. 2013; Ciavarella et al. 2018) are used. These are a historical ensemble (1960-2013; Historical) and factual (ACT) and counterfactual (a "natural" world without anthropogenic forcings; NAT) ensembles of 2018. We compare results from this factual-counterfactual analysis with those from a trend-based analysis of Historical, ensembles from EURO-CORDEX (Vautard et al. 2013; Jacob et al. 2014; Vrac and Vaittinada Ayar) (1971-2018) and RACMO (Aalbers et al. 2018; Lenderink et al. 2014) (1950-2018), and observations from E-OBS (1950-2018). A full model description is provided in the online supplemental information. Initially, we performed our analysis with the weather@home HadRM3P European-25 km setup (Massey et al. 2015) but found that this model overestimates the variability over all Europe for daily through seasonal-scale event statistics, and so it was omitted.

METHODOLOGY. We calculate the return period (RP) for the 2018 event in a distribution fit to E-OBS using the generalized extreme value (GEV) distribution to model TM1x and TM10x, and the generalized logistic distribution to empirically model TM90x throughout. Since the distribution of temperature extremes changes as the climate does, to account for the non-stationarity of the time series we first remove the trend attributable to low-pass-filtered globallyaveraged mean surface temperature (GMST, from Berkeley Earth; Rohde et al. 2013) in an ordinaryleast squares regression (the regression coefficient or trend is shown in the supplemental material in Fig. ES1; Diffenbaugh et al. 2017). We then find the temperature threshold corresponding to the RP in a distribution fit to the model's climatology. In the factual/counterfactual analysis, we do this by fitting parameters to a detrended (against GMST; trends shown in Figs. ES2c7-9) climatological ensemble of Historical plus 15 randomly sampled members of ACT. We finally calculate the probability $(P)$ of exceeding this climatological temperature threshold in distributions fit to the ACT and NAT ensembles and calculate the probability ratio, $\mathrm{PR}=P_{\mathrm{ACT}} / P_{\mathrm{NAT}}$, representing the increased likelihood of the 2018 event in the factual compared to the counterfactual world. Using estimated event probabilities rather than observed magnitudes constitutes a quantile bias correction (Jeon et al. 2016), minimizing model biases in the mean and variability of the temperatures analyzed. A description of uncertainty calculation and the trend-based analysis discussed below is included in the supplemental material.

RESULTS. Extreme daily heat events, measured by TM1x, are distributed heterogeneously throughout Europe (Fig. ES1i). This is paralleled in the factual/ counterfactual PRs seen in Fig. 1a, with large proportions of the Iberian Peninsula, the Netherlands, and Scandinavia experiencing events that were highly unlikely in a climate without anthropogenic influence. A similar result is found on the regional scale (Fig. 1d) with Scandinavia and the Iberian Peninsula respectively experiencing 1 -in-150 $[26-26,000]^{1}$ and 1-in-30 [9-550] year events in the current climate that were highly unlikely in the natural climate simulated in NAT. The remaining regions record maximum daily temperatures likely to be repeated within 4 years. Considering the whole of Europe, the likelihood of the 2018 maximum of daily European mean temperature occurring without climate change is zero. This result is consistent with Uhe et al. (2016) and Angélil et al. (2018), who showed that increasing spatial scale tends to increase the probability ratio.

Extreme 10-day heat events, TM10x, were also widespread in Europe, with the most extreme occurring in Scandinavia (Fig. ES1j). Regionally, the PRs become more uniform (Fig. 1d), although Scandinavia and the Iberian Peninsula still have very high bestestimate PRs of 185 [17-infinite] and 110 [18-56,000] respectively. The best-estimate PR for the average of Europe is still formally infinite.

\footnotetext{
${ }^{1}$ Numbers in brackets [ ] represent a 90\% confidence interval.
} 
TM1x
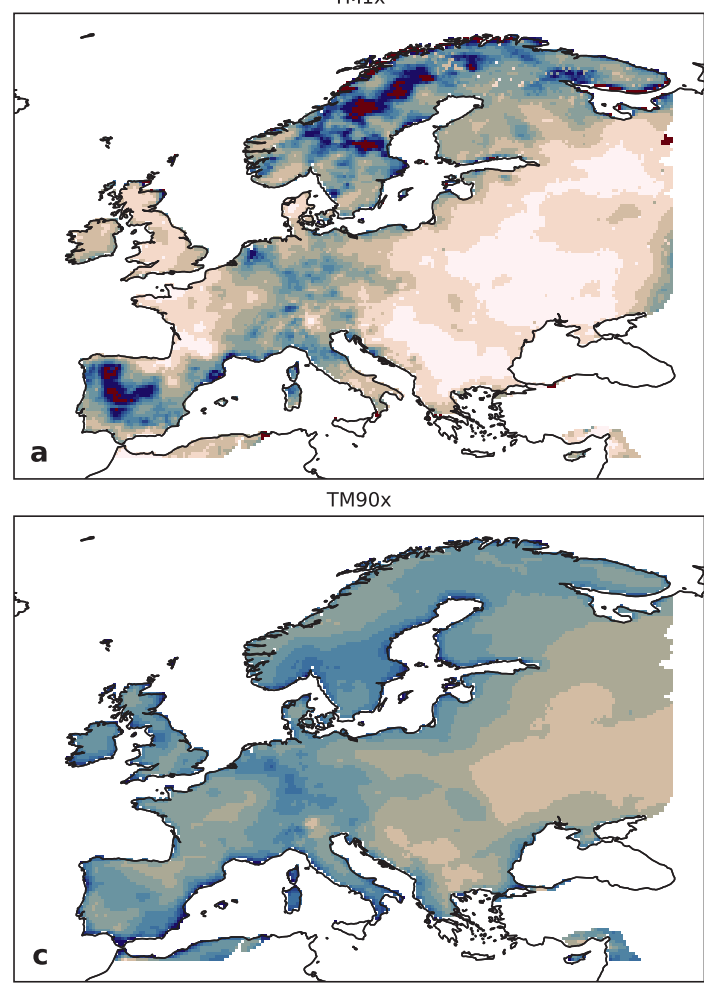

TM10x

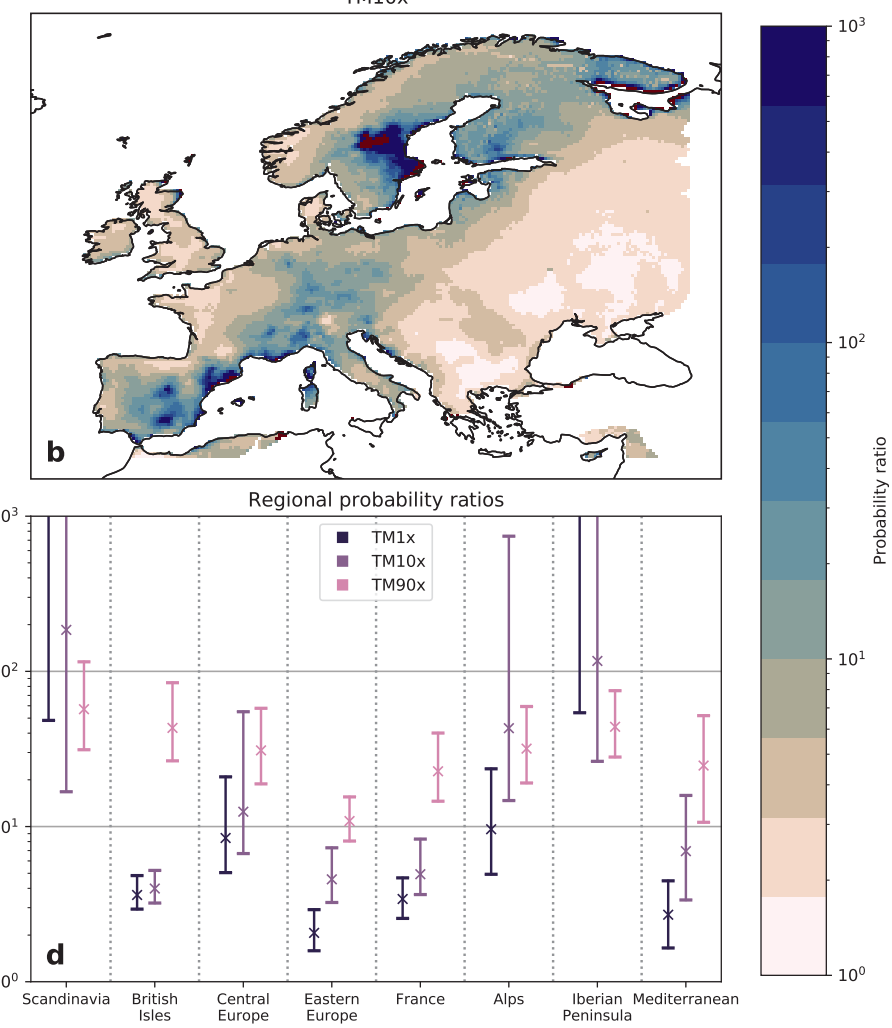

FIG. I. Probability ratios for the 2018 summer heat-event derived from HadGEM3-A factual/counterfactual simulations. (a)-(c) Maps of increased likelihood in the real world at gridbox scale for the three event time scales analyzed respectively. Note that the upper limit on the color scale is 1,000 and grid boxes with an infinite probability ratio are shown in dark red. (d) The regional probability ratios for the three time scales; the crosses denote the best estimate, and the bars denote the 5th-95th percentiles. Note that the best-estimate probability ratios for TMIx in Scandinavia and the Iberian Peninsula were infinite and 2,000 respectively.

The PR map for season-long heat events measured by TM90x is more uniform throughout Europe (Fig. 1c). Scandinavia, the British Isles, France, and central and eastern Europe, all of which experienced on the order of 1-in-10 year events (Fig. ES11), and the corresponding best-estimate PRs are between 10 and 100 for all regions (Fig. 1d), including those with lower return periods. The PR for the European average is 1,000 [500-2,000].

Trend-based analysis [Figs. ES1m-p (observations) and Fig. ES2b (models)] yields similar results, although we note that for HadGEM-3A this results in generally higher PRs, due to the linear trend with GMST in the climatology being greater than the difference between the two ensembles used in the factual/counterfactual analysis. Observational and model analysis contradict in some grid boxes in northern Scandinavia for TM1x and TM10x, since the observed best-estimate trend against GMST is negative, reducing the event probability for the presentday compared to the preindustrial climate, therefore yielding PRs of less than 1. Comparing the regional factual/counterfactual model with observational analysis (Fig. 1d vs Fig. ES1p) shows that the large observational uncertainties overlap with the model results: the difference could be due to natural variability affecting the small observational sample size. However, we are cautious of drawing any conclusions regarding the change in likelihood of extreme heat events as defined here for these locations.

The PR increases with the event statistic time scale for the majority of grid points and regions (shown in Fig. 1). Figure 2 illustrates the cause using the British Isles region: as the time scale increases, the event statistic distribution variance decreases, while the mean shift between the factual and counterfactual distributions remains constant. Figure ES1t shows that the similarity in trends with GMST between the three time scales is also true for the observations. The decrease in variance usually results in higher PRs, given a particular event return time, for the longer time scales. There are exceptions due to the bounded 

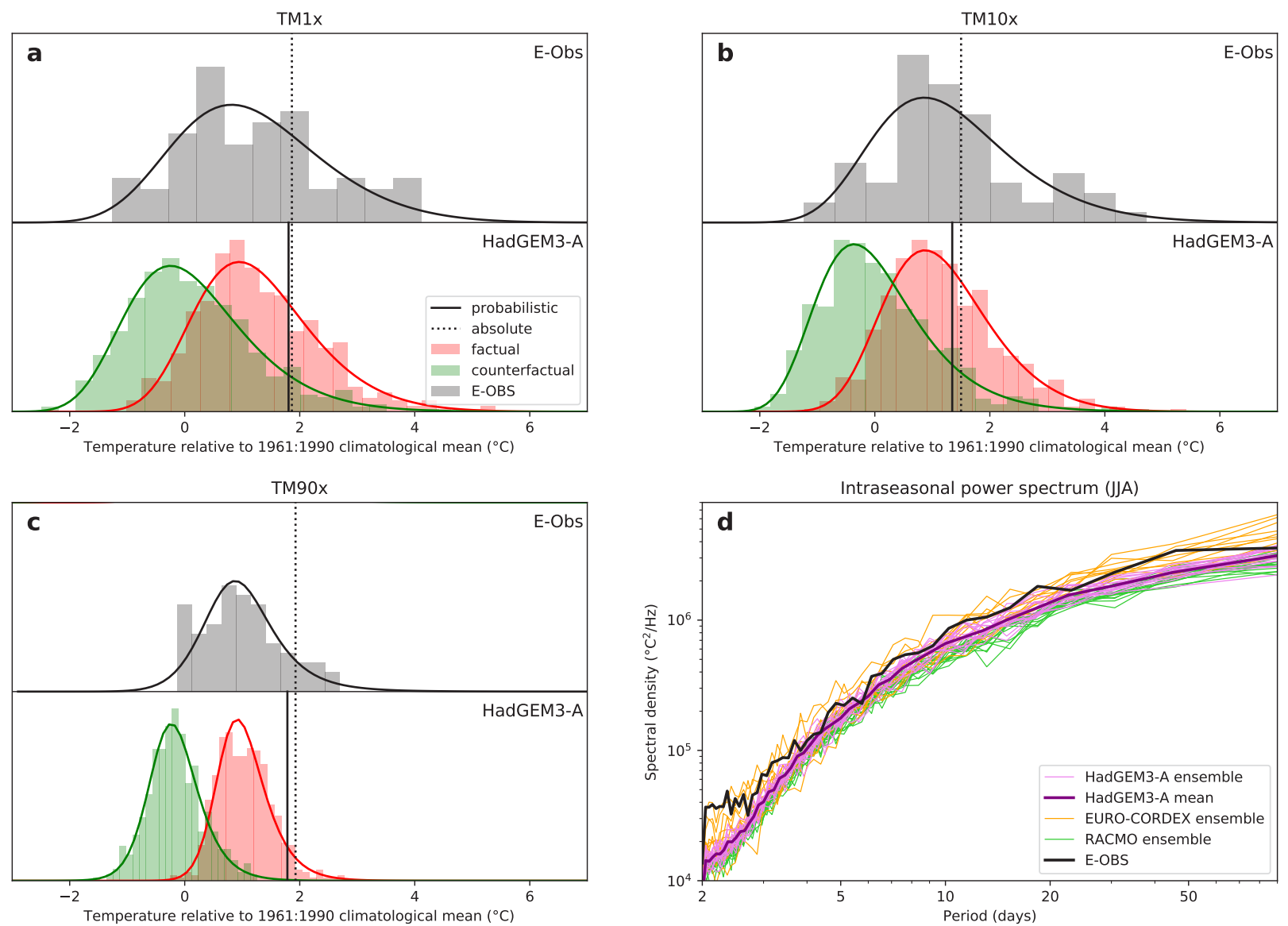

FIG. 2. (a)-(c) Probability density functions of the three temporal scales of event statistic for the British Isles, showing HadGEM3-A ACT (factual) and NAT (counterfactual) simulations, and observations from E-OBS; all as anomalies above the model or observed 196I:1990 mean climatology. Thick black lines show the 2018 event defined probabilistically as the HadGEM3-A Historical temperature threshold corresponding to the E-OBS return period; dotted black lines show the event defined in terms of the magnitude observed directly from E-OBS. (d) Periodograms of JJA daily mean temperature in the British Isles (seasonality and mean removed) calculated as the mean of intraseasonal periodograms for all available years. The HadGEM3-A power spectrum is calculated from the Historical ensemble.

upper tail of a GEV distribution with a negative shape parameter, resulting in the very high PRs for TM1x in Scandinavia, the Iberian Peninsula, and the Netherlands. The solid and dotted black lines compare the temperature thresholds when using event return periods to anomaly magnitudes in E-OBS. This explains why the TM90x PR is much higher than the other time scales for the British Isles: in addition to the decreased variance, the seasonal-scale heat event was more unusual than the other time scales, with a longer return period (10.6 [5.7-21] years) than TM10x (2.6 [1.8-3.9] years) and TM1x (3.6 [2.5-6.2] years). These factors together result in PRs of 3.6 [2.9-4.8] for TM1x and 43 [27-84] for TM90x. We suggest that the change in variance between the time scales used largely reconciles the differences between the
"2 to 5" and " 30 " times increases in likelihood found by the WWA and UKMO reports, with other methodological factors playing a minor role as we have demonstrated for the British Isles.Although higher return periods for TM90x do impact the PRs found, this effect is generally less significant than changes in variability between the time scales.

Figure 2 also demonstrates a relevant deficiency in the model: the model distributions are narrower than the observed distributions, meaning the model has lower variability than the real world. This reduced variance has a significant impact on attribution results (Bellprat et al. 2019) and means that the PRs for the British Isles presented here, especially for TM90x, are likely to be overestimated. Underrepresented variability often occurs in prescribed SST models 
(Fischer et al. 2018) and is visible in HadGEM-3A for many coastal locations over Europe (Figs. ES2a7-9). Figure $2 \mathrm{~d}$ shows the power spectrum of JJA summer temperatures over the British Isles, indicating that HadGEM3-A has similar spectral characteristics to E-OBS, but underrepresents the intraseasonal 2-m temperature variability at almost all frequencies, which will likely result in overestimated PRs. Power spectra for other model ensembles are shown for comparison, demonstrating that the fully bias-corrected EURO-CORDEX ensemble has the same variability characteristics and magnitude as the observations.

DISCUSSION. Our analysis highlights a key property of extreme weather attribution: the variance of the event definition used, both in terms of the statistic itself and its representation within any models used. The use of longer temporal event scales in general increases both the spatial uniformity and magnitude of the probability ratios found, consistent with Kirchmeier-Young et al. (2019), due to a decrease in variance compared to shorter scales. The difference in temporal scale between two reports concerning the 2018 summer heat is sufficient to explain the large discrepancy in attribution result between them. We find that several European regions experienced season-long heat events with a present-day return period greater than 10 years. The present-day likelihood of such events occurring is approximately 10 to 100 times greater than a "natural" climate. The attribution results also show that the extreme daily temperatures experienced in parts of Scandinavia, the Netherlands, and the Iberian Peninsula would have been highly unlikely without anthropogenic warming. The prescribed SST model experiments used here tend to underestimate the variability of temperature extremes near the coast, which may lead to the attribution results overstating the increase in likelihood of such extremes due to anthropogenic climate change (Bellprat et al. 2019). We aim to properly quantify the impact of the underrepresented variability in further work. Although here we have used an unconditional temperature definition for consistency with the studies we try to reconcile, we plan to further investigate the effect of including both the atmospheric flow context and other impact-related variables such as precipitation in the event definition, and address issues models might have with realistically simulating the physical drivers of heatwaves.

ACKNOWLEDGMENTS. We acknowledge the E-OBS dataset from the EU-FP6 project UERRA (http://www. uerra.eu) and the Copernicus Climate Change Service, and the data providers in the ECAI\&D project (https:// www.ecad.eu). We thank all of the volunteers who have donated their computing time to Climateprediction.net and weather@home.

\section{REFERENCES}

Aalbers, E. E., G. Lenderink, E. van Meijgaard, and B. J. van den Hurk, 2018: Local-scale changes in mean and heavy precipitation in western Europe, climate change or internal variability? Climate Dyn., 50, 4745-4766, https://doi.org/10.1007/s00382-0173901-9.

Angélil, O., and Coauthors, 2018: On the nonlinearity of spatial scales in extreme weather attribution statements. Climate Dyn., 50, 2739-2752, https://doi. org/10.1007/s00382-017-3768-9.

Bellprat, O., V. Guemas, F. Doblas-Reyes, and M. G. Donat, 2019: Towards reliable extreme weather and climate event attribution. Nat. Commun., 10, 1732, https://doi.org/10.1038/s41467-019-09729-2.

Cattiaux, J., and A. Ribes, 2018: Defining single extreme weather events in a climate perspective. Bull. Amer. Meteor. Soc., 99, 1557-1568, https://doi.org/10.1175/ BAMS-D-17-0281.1.

Christensen, J. H., and O. B. Christensen, 2007: A summary of the PRUDENCE model projections of changes in European climate by the end of this century. Climatic Change, 81 (S1), 7-30, https://doi. org/10.1007/s10584-006-9210-7.

Christidis, N., P. A. Stott, A. A. Scaife, A. Arribas, G. S. Jones, D. Copsey, J. R. Knight, and W. J. Tennant, 2013: A new HadGEM3-A-based system for attribution of weather- and climate-related extreme events. J. Climate, 26, 2756-2783, https://doi.org/10.1175/ JCLI-D-12-00169.1.

Ciavarella, A., and Coauthors, 2018: Upgrade of the HadGEM3-A based attribution system to high resolution and a new validation framework for probabilistic event attribution. Wea. Climate Extremes, 20, 9-32, https://doi.org/10.1016/j.wace.2018.03.003.

Cornes, R. C., G. van der Schrier, E. J. van den Besselaar, and P. D. Jones, 2018: An ensemble version of the E-OBS temperature and precipitation data sets. J. Geophys. Res., 123, 9391-9409, https://doi. org/10.1029/2017JD028200.

Diffenbaugh, N. S., and Coauthors, 2017: Quantifying the influence of global warming on unprecedented extreme climate events. Proc. Natl. Acad. Sci. USA, 114, 4881-4886, https://doi.org/10.1073/ pnas.1618082114

D’Ippoliti, D., and Coauthors, 2010: The impact of heat waves on mortality in 9 European cities: Results from 
the EuroHEAT project. Environ. Health, 9, 37, https:// doi.org/10.1186/1476-069x-9-37.

Fischer, E. M., U. Beyerle, C. F. Schleussner, A. D. King, and R. Knutti, 2018: Biased estimates of changes in climate extremes from prescribed SST simulations. Geophys. Res. Lett., 45, 8500-8509, https://doi. org/10.1029/2018GL079176.

Harris, C., 2018: Heat, hardship and horrible harvests: Europe's drought explained. Euronews, 8 December 2018, https://www.euronews.com/2018/08/10/ explained-europe-s-devastating-drought-and-thecountries-worst-hit.

Jacob, D., and Coauthors, 2014: EURO-CORDEX: New high-resolution climate change projections for European impact research. Reg. Environ. Change, 14, 563-578, https://doi.org/10.1007/s10113-013-0499-2.

Jeon, S., C. J. Paciorek, and M. F. Wehner, 2016: Quantile-based bias correction and uncertainty quantification of extreme event attribution statements. Wea. Climate Extremes, 12, 24-32, https:// doi.org/10.1016/j.wace.2016.02.001.

Johnston, C., 2018: Heatwave temperatures may top $45 \mathrm{C}$ in southern Europe. The Guardian, 4 August 2018, https://www.theguardian.com/world/2018/aug/04/ temperatures-in-southern-europe-top-45-heatwavespain-portugal.

Kirchmeier-Young, M. C., H. Wan, X. Zhang, and S. I. Seneviratne, 2019: Importance of framing for extreme event attribution: The role of spatial and temporal scales. Earth's Future, 7, 1192-1204, https:// doi.org/10.1029/2019EF001253.

Krikken, F., F. Lehner, K. Haustein, I. Drobyshev, and G. J. van Oldenborgh, 2019: Attribution of the role of climate change in the forest fires in Sweden 2018. Nat. Hazards Earth Syst. Sci. Discuss., https://doi. org/10.5194/nhess-2019-206.

Lenderink, G., B. J. van den Hurk, A. M. Klein Tank, G. J. van Oldenborgh, E. van Meijgaard, H. de Vries, and J. J. Beersma, 2014: Preparing local climate change scenarios for the Netherlands using resampling of climate model output. Environ. Res. Lett., 9, 115008, https://doi.org/10.1088/1748-9326/9/11/115008.

Massey, N., and Coauthors, 2015: weather@home-Development and validation of a very large ensemble modelling system for probabilistic event attribution.
Quart. J. Roy. Meteor. Soc., 141, 1528-1545, https:// doi.org/10.1002/qj.2455.

McCarthy, M., and Coauthors, 2019: Drivers of the UK summer heatwave of 2018. Weather, 74, 390-396, https://doi.org/10.1002/wea.3628.

NESDIS, 2018: Record summer heat bakes Europe. NOAA/NESDIS, 10 August 2018, https://www. nesdis.noaa.gov/content/record-summer-heatbakes-europe.

Press Office, 2018: Chance of summer heatwaves now thirty times more likely. Met Office News, 6 December 2018, https://www.metoffice.gov.uk/about-us/ press-office/news/weather-and-climate/2018/2018uk-summer-heatwave.

Publico, 2018: Neuve fallecidos por la ola de calor en Espana. Publico, accessed 17 August 2019, https:// www.publico.es/sociedad/nueve-fallecidos-olacalor-espana.html.

Rohde, R., and Coauthors, 2013: A new estimate of the average Earth surface land temperature spanning 1753 to 2011. Geoinf. Geostat. Overview, 1, 1, https:// doi.org/10.4172/2327-4581.1000101.

Uhe, P., F. E. L. Otto, K. Haustein, G. J. van Oldenborgh, A. D. King, D. C. H. Wallom, M. R. Allen, and H. Cullen, 2016: Comparison of methods: Attributing the 2014 record European temperatures to human influences. Geophys. Res. Lett., 43, 8685-8693, https://doi.org/10.1002/2016GL069568.

Vautard, R., and Coauthors, 2013: The simulation of European heat waves from an ensemble of regional climate models within the EURO-CORDEX project. Climate Dyn., 41, 2555-2575, https://doi.org/10.1007/ s00382-013-1714-z.

Vrac, M., and P. Vaittinada Ayar, 2017: Influence of bias correcting predictors on statistical downscaling models. J. Appl. Meteor. Climatol., 56, 5-26, https:// doi.org/10.1175/JAMC-D-16-0079.1.

Watts, J., 2018: Wildfires rage in Arctic Circle as Sweden calls for help. The Guardian. 18 July 2018, https:// www.theguardian.com/world/2018/jul/18/swedencalls-for-help-as-arctic-circle-hit-by-wildfires.

World Weather Attribution, 2018: Heatwave in northern Europe, summer 2018. 28 July 2018, https://www. worldweatherattribution.org/attribution-of-the2018-heat-in-northern-europe/. 